\title{
Lichen sclerosus in a radiated breast
}

\section{Olga Vujovic MD}

A 77-year-old woman with cancer of the left breast (T2NOM0) had undergone breast-conserving surgery and had received adjuvant hormonal treatment with anastrozole and radiation therapy. She had had a good cosmetic outcome with no discernable skin changes or breast pain. Two years after completion of the radiation treatments, severe discomfort developed in her left breast. The discomfort was associated with ivory-white patches with overlying telangiectasia and purpuric hemorrhages not seen with radiation dermatitis. A biopsy of the left breast confirmed lichen sclerosus. Treatment with betamethasone $0.05 \%$ cream resulted in some improvement (Figure 1). However, after six months, she still had pain and skin changes of the breast and elected to undergo a left mastectomy. Histopathology of skin from the breast is shown in Appendix 1 (available at www.cmaj.ca/cgi/content/full /cmaj.091800/DC1).

Lichen sclerosus usually occurs in women over the age of 50 and involves the anogenital area in $85 \%$ of affected patients. ${ }^{1}$ The most common extragenital sites are the neck, shoulders, upper back and chest. The exact cause of lichen sclerosus is not known, but it is associated with several autoimmune disorders, including alopecia areata and vitiligo. The Köbner phenomen can occur in lichen sclerosis, whereby lesions develop at sites of trauma, constant friction or old scars. ${ }^{2,3}$ Although radiation therapy causes trauma to skin, few instances of lichen sclerosus occurring several years after radiation therapy for breast cancer have been reported. ${ }^{4}$ In our patient, the lichen sclerosus at the site of radiation was likely the result of the Köbner phenomenon.

Although genital lichen sclerosus is associated with a small risk of squamous cell carcinoma (5\%), either vulvar or penile, the extragenital form is not. ${ }^{1}$

The mainstay of treatment is high-potency topical corticosteroids, which have shown good clinical response in various studies. ${ }^{3}$ Other treatment options include topical testosterone or progesterone, topical or oral retinoids, and surgery.

From the Department of Radiation Oncology, London Regional Cancer Program, London Health Sciences Centre, London, Ont.

\section{CMAJ 2010. DOI:10.1503/cmaj.091800}

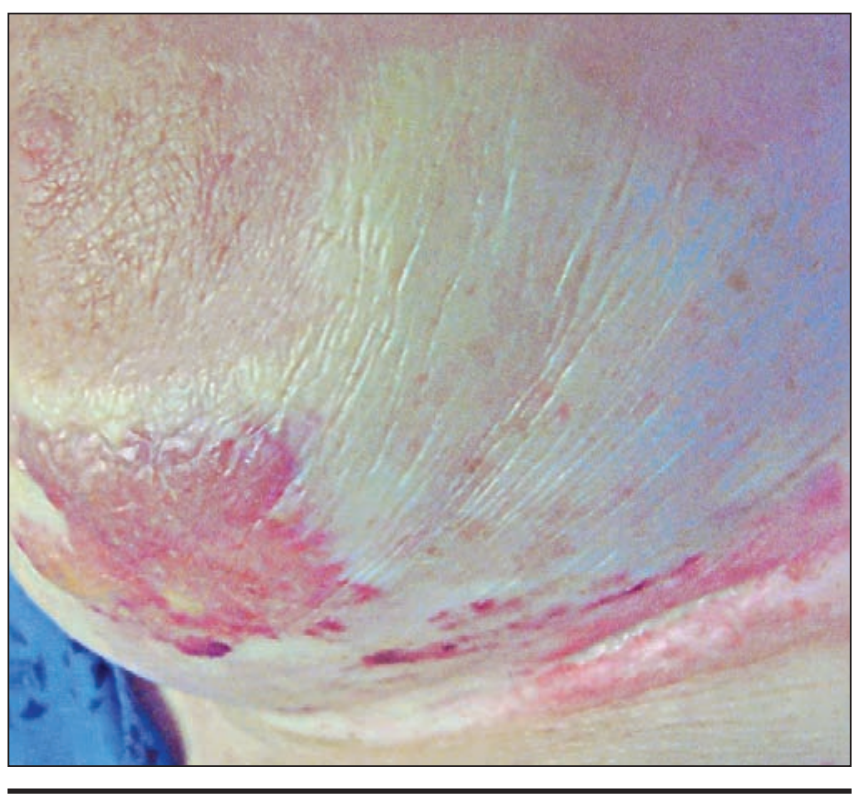

Figure 1: The left breast of a 77-year-old woman with lichen sclerosus, showing characteristic ivory-white patches and purpuric hemorrhages, two years after radiation therapy.

This article has been peer reviewed.

Competing interests: None declared.

\section{REFERENCES}

1. Powell JJ, Wojnarowska F. Lichen sclerosus. Lancet 1999;353:1777-83.

2. Meffert JJ, Davis BM, Grimwood RE. Lichen sclerosus. J Am Acad Dermatol 1995;32:393-416.

3. Val I, Amedia G. An overview of lichen sclerosus. Clin Obstet Gynecol 2005;48: 808-17.

4. Yates VM, King CM, Dave VK. Lichen sclerosus et atrophicus following radiation therapy. Arch Dermatol 1985;121:1044-7.

Clinical images are chosen because they are particularly intriguing, classic or dramatic. Submissions of clear, appropriately labelled high-resolution images must be accompanied by a figure caption and the patient's written consent for publication. A brief explanation (300 words maximum) of the educational significance of the images with minimal references is required. 